\title{
Plasma Vitellogenin in Free-Ranging Loggerhead Sea Turtles (Caretta caretta) of the Northwest Atlantic Ocean
}

\author{
Kimberly Smelker, ${ }^{1}$ Lauren Smith, ${ }^{1}$ Michael Arendt, ${ }^{2}$ Jeffrey Schwenter, ${ }^{2}$ \\ David Rostal, ${ }^{3}$ Kyle Selcer, ${ }^{4}$ and Roldán Valverde ${ }^{1}$ \\ ${ }^{1}$ Department of Biological Sciences, Southeastern Louisiana University, 808 North Pine Street SLU 10736, \\ Hammond, LA 70402, USA \\ ${ }^{2}$ Marine Resources Division, South Carolina Department of Natural Resources, 217 Fort Johnson Road, Charleston, SC 29412, USA \\ ${ }^{3}$ Department of Biology, Georgia Southern University, P.O. Box 8042, Statesboro, GA 30460, USA \\ ${ }^{4}$ Department of Biological Sciences and Center for Environmental Research and Education, Duquesne University, 600 Forbes Avenue, \\ Pittsburgh, PA 15282, USA \\ Correspondence should be addressed to Roldán Valverde; roldan.valverde@selu.edu
}

Received 18 November 2013; Accepted 15 January 2014; Published 27 February 2014

Academic Editor: Norman Ying Shiu Woo

Copyright ( 2014 Kimberly Smelker et al. This is an open access article distributed under the Creative Commons Attribution License, which permits unrestricted use, distribution, and reproduction in any medium, provided the original work is properly cited.

\begin{abstract}
Vitellogenin is the egg yolk precursor protein produced by oviparous vertebrates. As endogenous estrogen increases during early reproductive activity, hepatic production of vitellogenin is induced and is assumed to be complete in female sea turtles before the first nesting event. Until the present study, innate production of vitellogenin has not been described in free-ranging sea turtles. Our study describes circulating concentrations of vitellogenin in loggerhead sea turtles (Caretta caretta) from the Northwest Atlantic Ocean. We collected blood samples from juveniles and adults via in-water captures off the coast of the Southeast USA from May to August, and from nesting females in June and July at Hutchinson Island, Florida. All samples were analyzed using an in-house ELISA developed specifically to measure Caretta caretta vitellogenin concentration. As expected, plasma vitellogenin declined in nesting turtles as the nesting season progressed, although it still remained relatively elevated at the end of the season. In addition, mean vitellogenin concentration in nesting turtles was 1,000 times greater than that measured in samples from in-water captures. Our results suggest that vitellogenesis may continue throughout the nesting season, albeit at a decreasing rate. Further, vitellogenin detected in turtles captured in-water may have resulted from exposure to endocrine disrupting chemicals.
\end{abstract}

\section{Introduction}

Sea turtles are ancient reptiles that are fully adapted to marine life. The threatened and endangered status of these species has made research regarding their reproductive physiology a crucial component of conservation programs. However, several aspects of their reproductive physiology remain unclear. For instance, circulating plasma vitellogenin concentration has not been fully described in free-ranging reproductively active sea turtles. A comprehensive understanding of the vitellogenic seasonal cycle may allow us to identify the reproductive status of individuals and evaluate reproductive health.

Vitellogenesis is the process through which female oviparous vertebrates synthesize and sequester vitellogenin for the development of egg yolk [1]. Vitellogenin is synthesized in the liver and transported via the blood stream to the oocytes where it enters via endocytosis and is enzymatically cleaved into phosphovitins and lipovitellin, which are the major proteins contributing nutrients and lipids for the developing embryo [2]. Other proteins are also incorporated into the yolk such as immunoglobulins, albumin, cholecalciferol, and very-low-density lipoprotein [3]. Vitellogenesis is associated with an increase in the size of the liver, oviducts, and ovaries $[1,4-6]$ and an increase in plasma concentration of calcium, proteins, and lipids [68 ]. Hepatic production of vitellogenin is under control of estradiol- $17 \beta$ in oviparous vertebrates $[1,9]$. Upon exposure to exogenous estrogen, vitellogenin has been detected within 
a few hours in turtles, birds, and amphibians $[4,10,11]$ and reached maximum plasma concentration several days after exposure [4]. Vitellogenin continues to circulate in the blood long after initial production; after a single injection of estrogen, vitellogenin was still detectable over a month later in Chrysemys picta plasma [4] and over two months later in Lepidochelys kempii [12].

Multiple hormones are responsible for modulating the estrogenic induction of vitellogenesis. Progesterone has been shown to inhibit vitellogenin production, most likely acting at the liver $[1,2,13]$. Low concentrations of testosterone have also been shown to inhibit vitellogenin production [1]. Both progesterone and testosterone may function to cease vitellogenesis at the end of the ovarian cycle [14]. In contrast, progesterone may also contribute to the estrogenic induction of vitellogenesis through the expression of progesterone receptor $\mathrm{B}(\mathrm{PRB})$, which is present only during follicular growth and appears to nullify the inhibitory effect of progesterone receptor A (PRA) $[15,16]$. However, the specific functions of progesterone, PRA, and PRB during vitellogenesis remain uncertain. Pituitary hormones are also thought to play a role in vitellogenesis. Vitellogenin concentration was significantly elevated in hypophysectomized Chrysemys picta that received both estradiol and growth hormone (GH) injections in comparison to turtles that received only estradiol or only GH injections [17], suggesting that GH may synergize with gonadal hormones to promote vitellogenesis. Further, activation of the hypothalamo-pituitary-gonadal axis, which initiates vitellogenesis, may also involve luteinizing hormone (LH) in addition to leptin, an adipocyte hormone that varies seasonally in other reptiles but has not been thoroughly studied in sea turtles [18]. Uptake of vitellogenin by developing follicles was stimulated by exogenous follicle stimulating hormone (FSH) in the lizard Podarcis sicula [19]. While both LH and FSH are present in sea turtles, the role of FSH in the reproductive cycle of these marine reptiles remains unclear [20].

Reproductively active sea turtles exhibit a relatively sharp and abrupt increase in plasma estradiol-17 $\beta$ concentration several weeks prior to their reproductive migration $[8,21-$ 24], which then remains elevated for approximately four weeks [8]. Immediately prior to migrating, plasma estradiol concentration begins to decline and testosterone concentration increases sharply [20]. Since estradiol is responsible for vitellogenesis, it is likely that there is a concomitant increase in vitellogenin production several weeks prior to migration. Additionally, laparoscopic examination of loggerhead sea turtles (Caretta caretta) revealed the presence of vitellogenic follicles half the size of ovulatory follicles four months prior to the nesting season, indicating that vitellogenesis begins several months before the reproductive season [23]. Plasma estradiol and testosterone both decrease significantly as the nesting season progresses [21, 25], suggesting that vitellogenin production is complete prior to the first nesting event in sea turtles. Plasma calcium concentration in nesting leatherbacks (Dermochelys coriacea) remains relatively low and constant throughout the nesting season, which may also indicate that vitellogenesis does not continue after the first nesting event [8].
Understanding the vitellogenic cycle in sea turtles could provide insight into other aspects of sea turtle physiology. For instance, the process of vitellogenesis requires the mobilization of significant energy reserves; therefore, production of vitellogenin is related to maternal body condition [7]. Initial concentration of vitellogenin in a nesting female could be an indicator of the quality and quantity of food available during internesting periods [26]. Likewise, vitellogenin concentration may also be an indicator of clutch size and frequency in nesting females. Since vitellogenesis is a process that occurs over several months [23], plasma vitellogenin concentration could be used as a biomarker of reproductive development in juvenile and recrudescing sea turtles. In addition, vitellogenin is considered a biomarker of exposure to endocrine disrupting chemicals (EDCs) in many species [27]. Understanding the natural production of vitellogenin in sea turtles may support the use of this molecule as a bioindicator of reproductive disruption in sea turtles.

To better understand the vitellogenic cycle in sea turtles we have developed an enzyme-linked immunosorbent assay (ELISA) specific for loggerhead sea turtle vitellogenin, and we have analyzed plasma collected from loggerheads inhabiting the Northwest Atlantic Ocean. Within this area there is one of the highest aggregations of loggerhead nesting in the world, with the majority of nesting occurring along the US coast from Virginia to Florida. Some nesting also occurs in the Gulf of Mexico, Caribbean, and Central America [28]. Posthatchlings use the North Atlantic Gyre to help them reach Northeast Atlantic waters where they spend several years foraging and growing before returning to the Northwest Atlantic [29]. Males spend their entire lives at sea, while females return to their natal beaches once they are reproductively mature [30]. Females emerge onto the beach to lay a clutch of eggs from one to seven times in one nesting season and typically do not return to nest for another two to four years [30]. On the Florida coast, the loggerhead nesting season lasts up to six months, from April to mid-September. It is unknown what circulating vitellogenin profiles look like in the life cycle of the loggerhead sea turtle.

This study describes the circulating concentration of vitellogenin in nesting and nonnesting female, male, and juvenile loggerhead sea turtles from the Northwest Atlantic Ocean. Our hypothesis was that circulating vitellogenin concentration would parallel the pattern seen in estradiol concentration in sea turtles. Specifically, we expected vitellogenin to only be detected in reproductively active females, and for the concentration to be highest at the beginning of the nesting season and then decline rapidly as the nesting season progressed.

\section{Materials and Methods}

2.1. Sample Collection. The National Marine Fisheries Service (NMFS) and U.S. Fish and Wildlife Service (USFWS) have designated nine distinct population segments (DPS) of loggerhead sea turtles, four of which are characterized by the International Union for Conservation of Nature (IUCN) as endangered and five as threatened [31]. Our study focuses 
on neritic and nesting loggerheads from the Northwest Atlantic DPS. Loggerheads of the Northwest Atlantic DPS are classified as threatened and include turtles within the area north of the equator and east of $60^{\circ} \mathrm{W}$, south of $40^{\circ} \mathrm{N}$ [31]. In the neritic zone of the eastern US, nearly all loggerhead turtles are immature, typically between 40 and $80 \mathrm{~cm}$ straight carapace length (SCL) $[32,33]$. Nesting females on the US east coast are generally between 80 and $100 \mathrm{~cm}$ SCL [34-37]. The minimum carapace length for adult turtles is difficult to discern, but the Turtle Expert Working Group uses $82 \mathrm{~cm} \mathrm{SCL}$ to designate adult size [38]. For this study, we aimed to sample turtles in the neritic zone to describe vitellogenin in immature turtles. Additionally, we captured foraging adult females, in an effort to describe vitellogenin production prior to the reproductive season and during the internesting period.

Samples were collected from in-water captured turtles by the South Carolina Department of Natural Resources under Section 10(a)(1)(A) permits 1540 and 15566, GADNR permit 21303 , and FWC permits 163. Samples were collected from nesting females under Florida Fish and Wildlife Commission permit 152 and Southeastern Louisiana University Institutional Animal Care and Use Committee protocol 0013. All blood samples were collected from the cervical sinus, using a 21 gauge, 1.5 inch needle, and heparinized vacutainer tube. Blood collection followed the protocol outlined by Owens and Ruiz [39].

In-water captures occurred from May to August in 2008 and from May to July in 2009. Beginning the sample season in May allowed the possibility of capturing larger female turtles $(>75 \mathrm{~cm} \mathrm{SCL})$ that were going to nest later in the season. Research vessels were fitted with NMFS turtle nets (paired $18.3 \mathrm{~m}$ nets) that were trawled for 20 -minute periods. All sampling procedures occurred in coastal waters (4.6$17.0 \mathrm{~m}$ deep) between Winyah Bay, South Carolina, and St. Augustine, Florida, USA (Figure 1). Upon capture, we assessed the turtles for general health and body condition before collecting blood and recording several morphometric measurements from each. We then tagged all turtles and released them into the wild. We centrifuged the blood and stored it in liquid nitrogen at sea; then, we stored it in a $-80^{\circ} \mathrm{C}$ freezer until analysis. A more thorough description of the inwater sampling protocol was given by Arendt et al. [40].

We collected blood samples at night from nesting females at Hutchinson Island, Florida, (Figure 1) from June 6 to August 14, 2008. After oviposition, we tagged turtles with Inconel flipper tags from the Cooperative Marine Turtle Tagging Program and recorded minimum and maximum SCL and straight carapace width (SCW; $\mathrm{cm}$ ). To collect blood we briefly restrained the turtles after they had successfully laid their eggs. We stored blood on ice until it was centrifuged and kept plasma frozen $\left(-80^{\circ} \mathrm{C}\right)$ until analysis.

2.2. Plasma Hormone Concentration. We used circulating plasma testosterone concentration to determine the sex of inwater captured turtles as follows: female, $<400 \mathrm{pg} \mathrm{mL}^{-1}$; male, $>500 \mathrm{pg} \mathrm{mL}^{-1}$; and unknown, $400-500 \mathrm{pg} \mathrm{mL}^{-1}$ [40]. We measured testosterone via radioimmunoassay (RIA) similar to that described by Blanvillain et al. [41]. We extracted

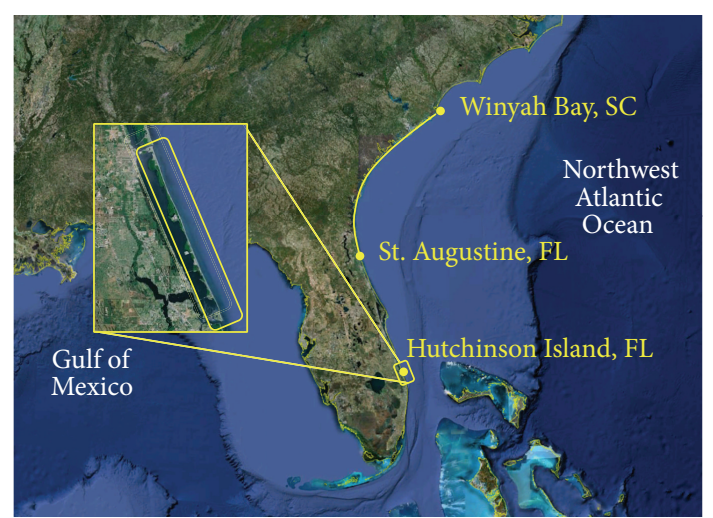

FIGURE 1: Map showing location of sample collection sites. Samples were collected from turtles captured in water from Winyah Bay, SC to St. Augustine, FL. Samples from nesting females were collected on Hutchinson Island, FL. Image from Google Maps (ㄷ 2013 Google Inc.).

between 10 and $500 \mu \mathrm{L}$ of plasma with $4 \mathrm{~mL}$ diethyl ether and assayed in duplicate. We prepared a standard curve with known concentrations of testosterone ranging from 19.5 to $1250 \mathrm{pg}$ per tube (Sigma-Aldrich, St. Louis, MO). We added the antibody and tritiated hormone (Esoterix, Inc., Austin, TX and PerkinElmer, Inc., Waltham, MA) to the samples, standards, and controls accordingly. We separated the unbound hormone in each tube using dextran-coated charcoal and centrifuged all tubes to separate bound and unbound fractions. We measured radioactivity from the tritiated hormone in the supernatant in a Wallac 1409 liquid scintillation counter and determined concentrations of native testosterone in the samples using the RIA Software (P. Licht, University of California, Berkeley). We measured circulating plasma estradiol-17 $\beta$ concentration in samples from in-water captures as well. Samples were ether-extracted following the procedure described above. We measured estradiol-17 $\beta$ concentration from in-water captures using a commercial ELISA kit (Cayman Chemical, Ann Arbor, MI), according to manufacturer's specifications.

We quantified circulating plasma testosterone in samples from nesting females using a commercial ELISA kit (Cayman Chemical, Ann Arbor, MI). We used the ELISA technique due to lack of resources (i.e., time, personnel, sample volume, etc.); although different from the RIA, both methods yielded comparable results. We added between 3 and $20 \mu \mathrm{L}$ of sample to $100 \mu \mathrm{L}$ EIA buffer in a glass test tube and extracted with $400 \mu \mathrm{L}$ of ether; we then vortexed the solution and flashfroze it in a dry ice/ethanol bath. We decanted the ether fraction into a clean test tube and repeated the whole process. We dried ether extracts under $\mathrm{N}_{2}$ gas in a $37^{\circ} \mathrm{C}$ water bath. We reconstituted samples with between $180 \mu \mathrm{L}$ and $480 \mu \mathrm{L}$ EIA buffer, depending on the original extraction volume. We ran samples through the testosterone kit according to manufacturer's specifications. Due to lack of resources, we did not measure estradiol-17 $\beta$ in samples from nesting females; however, estradiol was measured in several other studies on nesting sea turtles [8,21-23], including nesting loggerheads 
[24], and data show that estradiol exhibits a nearly $10 \mathrm{X}$ lower concentration during nesting in relation to mating, with surges nearing $700 \mathrm{pg} / \mathrm{mL}$ after every nesting event [24].

\subsection{Purification of Vitellogenin and Generation of Vitellogenin} Antibody. We pooled plasma from adult female loggerhead sea turtles to maximize protein load on the column and then fractionated it using a DEAE chromatography procedure that was previously effective for purification of Xenopus laevis vitellogenin [42]. We ran the procedure on a BioRad Econo Chromatography system (BioRad, Melville, NY) using a $1.0 \times$ $15 \mathrm{~cm}$ column filled with Macro-Prep DEAE Suport (BioRad). The equilibration buffer was $25 \mathrm{mM}$ Tris- $\mathrm{HCl}, \mathrm{pH}$ 7.5. The gradient buffer was $500 \mathrm{mM} \mathrm{NaCl}$ in equilibration buffer. We pooled plasma from 5 individuals, diluted 1:1 vol : vol in equilibration buffer ( $200 \mu \mathrm{L}$ total volume), and loaded onto the column. We washed the column with $30 \mathrm{~mL}$ equilibration buffer to remove proteins that did not adhere to the DEAE. We ran a linear gradient from 0 to $500 \mathrm{mM} \mathrm{NaCl}$ through the column using a total volume of $90 \mathrm{~mL}$. We monitored protein by UV absorbance at $280 \mathrm{~nm}$ throughout the chromatography run. We collected fractions $(3 \mathrm{~mL})$ throughout the procedure. We determined protein yield separately for each fraction by Coomassie protein assay. We evaluated fractions that contained significant amounts of protein by denaturing polyacrylamide gel electrophoresis.

To generate our ELISA standard, we pooled and dialyzed DEAE fractions found to contain vitellogenin $(210 \mathrm{kDa}$ protein) against DEAE equilibration buffer overnight using Spectra/Por 1 dialysis membrane (Spectrum, Houston, TX). To increase standard purity after this dialysis step, we ran the pooled-dialyzed fractions for a second time on the DEAE column using the same conditions as for serum. We pooled, dialyzed against water, and stored the resulting vitellogenincontaining fractions at $-20^{\circ} \mathrm{C}$ until use. We determined the protein concentration of the purified loggerhead sea turtle vitellogenin by Coomassie protein assay.

Covance (Princeton, NJ) prepared antisera against purified C. caretta vitellogenin in two rabbits using standard methodologies in a 77-day protocol. Rabbits were prebled on day 0 and then injected with $250 \mu \mathrm{g}$ of purified vitellogenin in Freund's Complete Adjuvant. Rabbits were boosted on day 21 with 125 micrograms of vitellogenin in Freund's Incomplete Adjuvant. Subsequent boosts were performed on days 42 and 63. Production bleeds of $20 \mathrm{~mL}$ serum were taken on days 31, 52, and 73. A terminal bleed was performed on day 77 . Antisera from the two rabbits performed quite well in ELISA titer assays using $1 \mu \mathrm{g} / \mathrm{mL}$ purified vitellogenin as the coating antigen and the antiserum diluted from $1: 500$ to $1: 1 \times 10^{7}$. The $50 \%$ titers were calculated to be $1: 66,000$ and $1: 43,000$ for the two rabbits, as compared to $<1: 100$ for the negative control. These values are considered good and average titers, respectively. Antisera were frozen at -80 until use.

2.4. Quantifying Vitellogenin. We used two solutions of purified loggerhead vitellogenin to create standard curves for two separate ELISAs. Standards and samples were plated in duplicate $(100 \mu \mathrm{L}$ of solution per well) on 96-well flat bottom polystyrene microtiter plates (Thermo Fisher Scientific, Inc.). We did not dilute plasma samples from in-water captures before analyses. We diluted standards and plasma samples from nesting females in phosphate buffered saline (PBS) solution ( $\mathrm{pH}$ 7.4). We diluted plasma samples from nesting females $1: 10,000,1: 20,000$, and $1: 25,000$ to ensure that the optical density (O.D.) would be within the linear portion of the standard curve.

Once we plated standards and samples, we covered and placed the plate in a sealed plastic container with a small cup of water and incubated overnight $(18 \mathrm{~h})$ at $4^{\circ} \mathrm{C}$. We washed plates three times with $150 \mu \mathrm{L}$ of PBS and blocked with a solution of PBS and 5\% nonfat dry milk (Blotto) for $1 \mathrm{~h}$ at room temperature on a rotating platform. We preincubated the anti-loggerhead vitellogenin antibody $(1: 1,000)$ with male Lepidochelys olivacea plasma in Blotto $(1: 2,000)$ for $1 \mathrm{~h}$ at $4^{\circ} \mathrm{C}$. This was done to ensure maximum specificity of the antibody. We washed plates with PBS three times before coating with the preadsorbed loggerhead vitellogenin antibody $(1: 30,000)$ and incubated on a rotating platform for $2 \mathrm{~h}$ at room temperature. After washing again, we incubated plates with $100 \mu \mathrm{L}$ of a goat anti-rabbit IgG coupled to horseradish peroxidase (Bio-Rad Laboratories, Inc.) diluted in Blotto $(1: 2,000)$ and then incubated on a rotating platform for $2 \mathrm{~h}$ at room temperature. After a final wash step, we added $100 \mu \mathrm{L}$ TMB Peroxidase EIA Substrate (Bio-Rad Laboratories, Inc.) to each well and incubated for $10 \mathrm{~min}$ at room temperature. The color development reaction was stopped by adding $100 \mu \mathrm{L}$ of $1 \mathrm{~N} \mathrm{H}_{2} \mathrm{SO}_{4}$. We read plates on a Bio-Rad Model 550 Microplate reader at $450 \mathrm{~nm}$. We calculated vitellogenin concentration using the general four-parameter logistic nonlinear regression model: $y=\max +(\min -\max ) /\left(1+\left(x /\right.\right.$ inflection point $\left.\left.\mathrm{till}^{\text {slope }}\right)\right)$. We serially diluted $(1: 100$ to $1: 128,000)$ plasma from a male turtle to determine the percent recovery of vitellogenin, and added a known amount of purified vitellogenin to each dilution. We compared the known amount of vitellogenin to the vitellogenin measured in the spiked samples.

2.5. Statistical Analyses. We used scatter plots to visualize the relationships between vitellogenin concentration and the parameters available to us (SCL, weight, testosterone concentration, and estrogen concentration). Due to unequal variances, we used nonparametric statistics for analyses and considered probabilities of $P<0.05$ as significant. We log-transformed the data in order to meet the statistical assumptions for simple linear regression between vitellogenin $(y)$ and SCL, weight, testosterone concentration, or estrogen concentration $(x)$. We used a Kruskal-Wallis one-way analysis of variance to compare mean vitellogenin concentration and mean testosterone concentration during each two-week interval of sampling nesting females. We used the same test to compare detectable vitellogenin concentration (see Section 3.1 for definition) during each month of in-water captures. We used Tukey tests for post hoc analyses. We used the Wilcoxon rank test to compare detectable mean vitellogenin in males and females from the in-water capture group. We compared mean vitellogenin in nesting turtles 
to mean vitellogenin in in-water capture turtles using a Student's $t$-test. We used a two-sample $t$-test to compare mean vitellogenin in false crawl females and nesting females at Hutchinson Island. We performed statistics using PASW Statistics 18 (SPSS, Inc.) and Sigma Plot 11.0 (Systat Software, Inc.), and all figures were created using SigmaPlot 11.0. Statistics are reported as mean \pm 1 standard error (SE).

\section{Results}

3.1. Validation and Specificity of the Vitellogenin ELISA. The vitellogenin standard curve for the assay used to analyze samples from in-water captures ranged from $0.3 \mu \mathrm{g} \mathrm{mL} L^{-1}$ to $170 \mu \mathrm{g} \mathrm{mL}^{-1}$ and the detection limit was estimated at $3.5 \mu \mathrm{g} \mathrm{mL}^{-1}$. The detection limit for each standard curve was estimated as two standard deviations of the mean vitellogenin concentration calculated from the mean blank absorbance readings for each plate. The average intra-assay $\mathrm{CV}$ for these assays was $8.1 \%$ and the average interassay CV was $11.8 \%$ $(n=24)$. The assay used to analyze the samples from nesting females had a working range of $0.04 \mu \mathrm{g} \mathrm{mL}^{-1}$ to $20 \mu \mathrm{g} \mathrm{mL}^{-1}$ and the detection limit was estimated at $0.2 \mu \mathrm{g} \mathrm{mL}^{-1}$. For these assays, the average intra-assay $\mathrm{CV}$ was $7.3 \%$ and the average interassay CV was $12.3 \%(n=19)$. Recovery of purified vitellogenin averaged $92 \%$.

3.2. In-Water Captures. Sex of each turtle was determined by testosterone concentration, as indicated in Section 2.2. Testosterone ranged from 43.6 to $10413 \mathrm{pg} \mathrm{mL}^{-1}$ in females and from 515.6 to $18800 \mathrm{pg} \mathrm{mL}^{-1}$ in males. Estrogen ranged from 3.18 to $4405.3 \mathrm{pg} \mathrm{mL}^{-1}$ in females and from 3.08 to $3463.3 \mathrm{pg} \mathrm{mL}^{-1}$ in males. After screening blood samples from all 361 turtles captured using the vitellogenin ELISA, only 22 had detectable plasma vitellogenin: 15 females, 5 males, and 2 of unknown sex. Mean vitellogenin concentration in turtles captured in-water was $6.0 \pm 0.64 \mu \mathrm{g} \mathrm{mL}^{-1}(n=21)$. One turtle sampled in May 2009 had a vitellogenin concentration of $146 \mu \mathrm{g} \mathrm{mL}^{-1}$, significantly higher than that detected in turtles sampled in June and July (Figure 2). This individual was a female turtle with a SCL approximately $93 \mathrm{~cm}$, and her vitellogenin concentration was not included in calculating the overall mean for this group. The mean SCL of all 361 turtles captured was $69.2 \pm 0.4 \mathrm{~cm}$ and ranged between 50.1 and $93.6 \mathrm{~cm}$. Only 21 of the 361 turtles were considered to be of adult size with an SCL greater than $82 \mathrm{~cm}$.

There was neither a significant difference in detectable vitellogenin in June compared to July $\left(5.36 \pm 0.25 \mu \mathrm{g} \mathrm{mL}^{-1}\right.$, $n=13$ and $7.03 \pm 1.63 \mu \mathrm{g} \mathrm{mL}^{-1}, n=8$, respectively; $U$ $=48.5, P=0.526$; Figure 2 ) nor a significant difference between vitellogenin detected in males compared to females $\left(4.98 \pm 0.41 \mu \mathrm{g} \mathrm{mL}^{-1}, n=5\right.$ and $5.54 \pm 0.54 \mu \mathrm{g} \mathrm{mL}^{-1}, n=14$, respectively; $U=33.0, P=0.89$ ). There was no significant linear relationship between vitellogenin concentration and SCL, mass, time of day, or plasma testosterone or plasma estradiol concentrations.

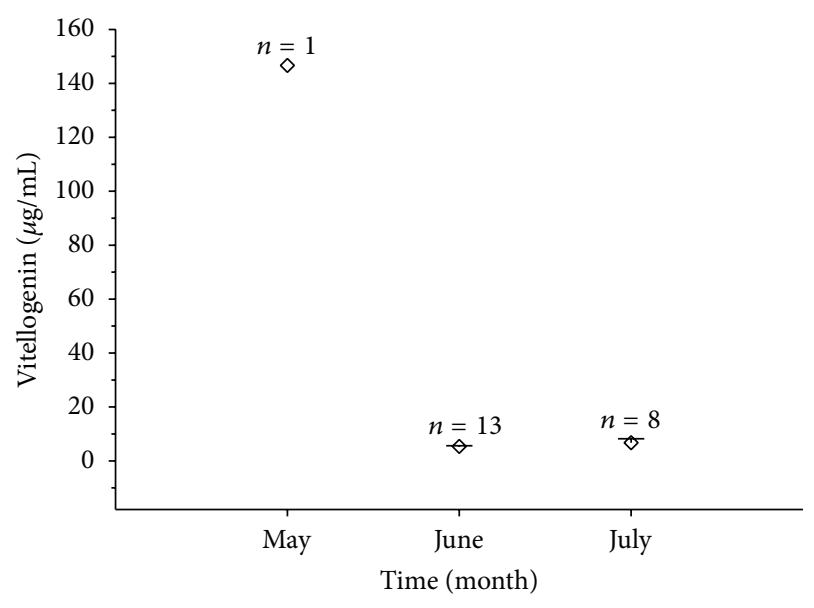

FIgure 2: Mean detectable vitellogenin concentration in turtles captured in water in 2008 and 2009. There was no significant difference in mean detectable vitellogenin in samples from in-water captures in June and July $(P>0.05)$. One individual sampled in May 2009 (female, $\mathrm{SCL}=93 \mathrm{~cm}$ ) had a substantially higher concentration of vitellogenin in comparison to turtles sampled in June and July. Error bars represent the standard error of the mean.

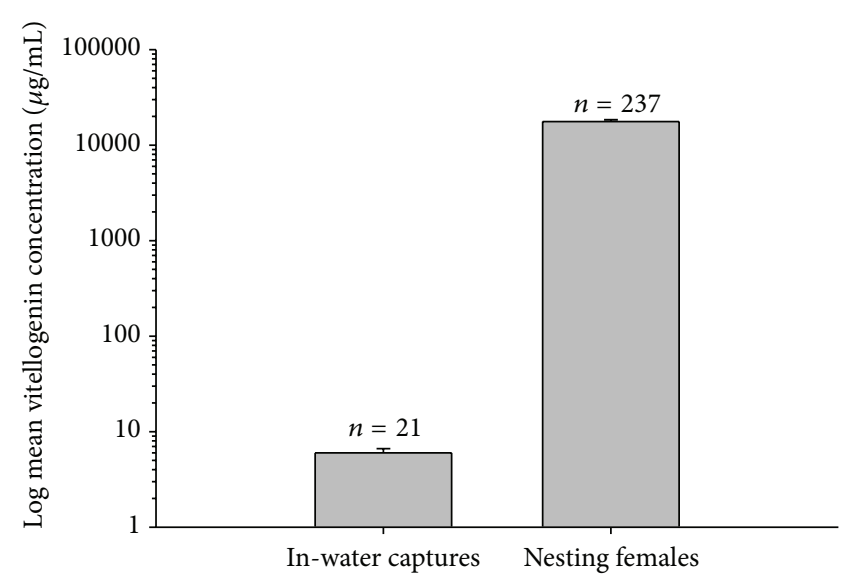

FIGURE 3: Overall mean plasma vitellogenin concentration measured in turtles from in-water captures in 2008 and 2009, and in nesting females sampled in 2008. Error bars represent the standard error of the mean. The mean vitellogenin concentration measured in nesting females was significantly higher than the mean vitellogenin concentration measured in samples from in-water captures $(P<$ $0.001)$.

3.3. Nesting Females. All 237 turtles sampled at Hutchinson Island, FL, had detectable vitellogenin with concentrations ranging from 1.3 to $96 \mathrm{mg} \mathrm{mL}^{-1}\left(18 \mathrm{mg} \mathrm{mL}^{-1} \pm\right.$ $\left.0.83 \mathrm{mg} \mathrm{mL}^{-1}\right)$. The mean vitellogenin concentration in nesting females was 1,000-fold greater than that detected in samples from the in-water captures $(t=-6.306$, df $=$ 256, $P<0.001$; Figure 3). Vitellogenin concentration decreased in nesting females as the nesting season progressed (Figure 4(a)). Vitellogenin concentration was significantly greater in nesting turtles sampled in June $(25.1 \pm$ $1.4 \mathrm{mg} \mathrm{mL}^{-1}, n=93$ ) compared to that measured in turtles caught in July and August $\left(13.1 \pm 1.03 \mathrm{mg} \mathrm{mL}^{-1}, n=109\right.$ and 


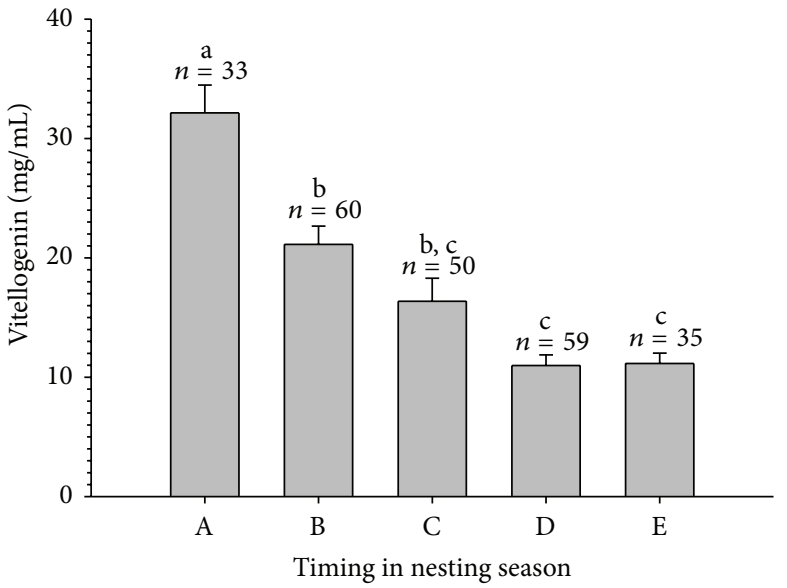

(a)

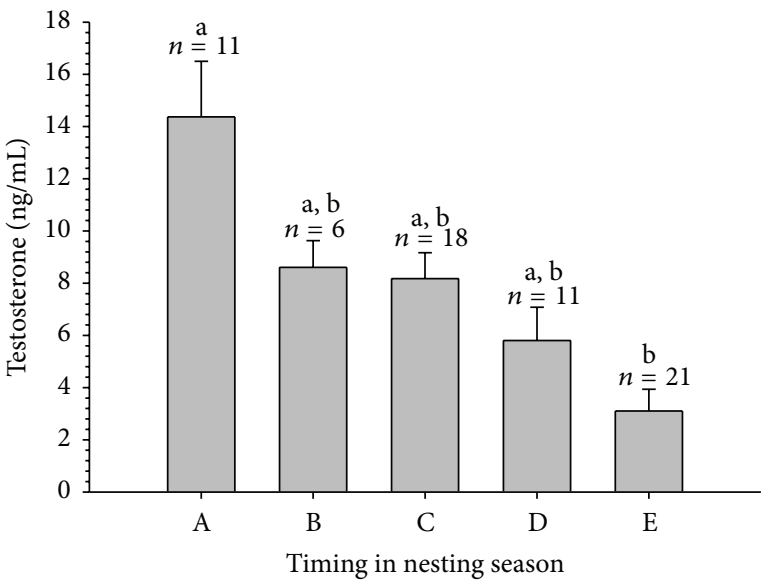

(b)

FIGURE 4: (a) Mean vitellogenin and (b) mean testosterone concentrations measured in nesting females over the nesting season were parsed every two weeks. Error bars represent the standard error of the mean and different letters represent significantly different groups. $(\mathrm{A}=$ Beginning June-Mid June; $\mathrm{B}=$ Mid June-End June; $\mathrm{C}=$ Beginning July-Mid July; $\mathrm{D}=$ Beginning August-Mid August; $\mathrm{E}=$ Beginning AugustMid August.) Both testosterone and vitellogenin concentrations decreased in nesting females as the nesting season progressed. Vitellogenin concentration was significantly higher in nesting turtles sampled in June compared to those measured in turtles caught in July and August. Testosterone concentration was significantly higher in nesting females sampled during the first two weeks of June in comparison to the end of June and all of July and beginning of August.

$11.1 \pm 0.86 \mathrm{mg} \mathrm{mL}^{-1}, n=35$, respectively; $H=62.151, \mathrm{df}=2$, $P<0.001)$. Nesting females that successfully oviposited had a slightly higher mean vitellogenin concentration $(17.86 \pm$ $0.92 \mathrm{mg} \mathrm{mL}^{-1}, n=193$ ) in comparison to nesting females that false-crawled $\left(16.31 \pm 1.95 \mathrm{mg} \mathrm{mL}^{-1}, n=44\right)$, but this difference was not significant.

Testosterone concentration was measured in 67 samples from nesting females chosen at random, across the season. Mean testosterone was $7.25 \pm 0.72 \mathrm{ng} \mathrm{mL}^{-1}$ and it declined over the course of the nesting season (Figure 4(b)). Highest testosterone concentration was measured in females nesting in June with a mean value of $12.34 \pm 1.55 \mathrm{ng} \mathrm{mL}^{-1}(n=$ 17 ), and it was significantly higher than testosterone concentration measured in females nesting in July and August, with mean values of $7.28 \pm 0.80 \mathrm{ng} \mathrm{mL}(n=29)$ and $3.10 \pm 0.83 \mathrm{ng} \mathrm{mL}(n=21)$, respectively, $(H=26.46$, $\mathrm{df}$ $=4, P<0.001)$. Testosterone was significantly correlated with vitellogenin concentration in nesting females $\left(r^{2}=0.225\right.$, $P<0.001$; Figure 5).

\section{Discussion}

4.1. Nesting Females. Plasma concentration of vitellogenin declined as the nesting season progressed, which paralleled the trend reported for plasma estradiol concentration in nesting sea turtles $[8,21-24]$. These results were expected since estradiol is responsible for inducing vitellogenesis in sea turtles and other oviparous vertebrates [1, 12, 43]. In addition, the concentrations of vitellogenin we report for nesting females bracketed the concentration measured in a single individual nesting green sea turtle Chelonia mydas (4.6 $\mathrm{mg} \mathrm{mL}^{-1}$ ) in another study [44].

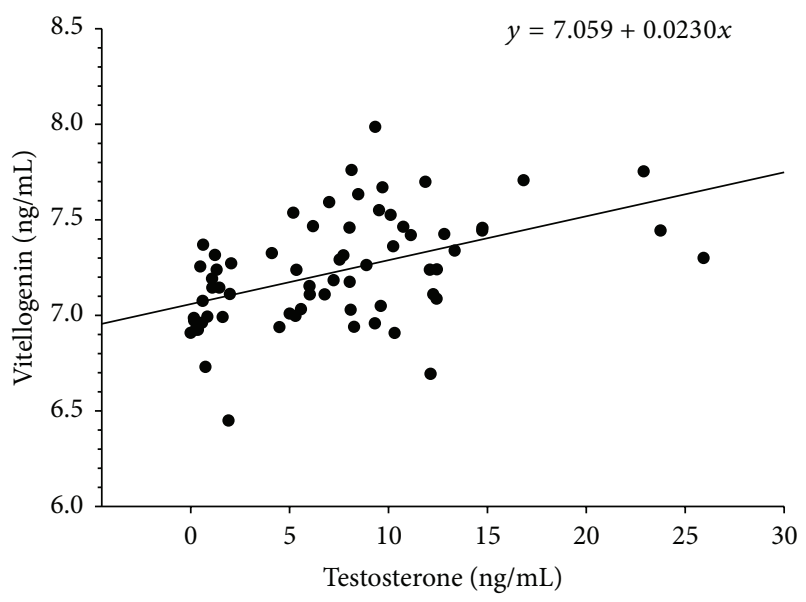

FIGURE 5: Plasma testosterone concentration in relation to log vitellogenin concentration in nesting females. There was a significant positive linear correlation between vitellogenin and testosterone concentration $\left(r^{2}=0.225, P<0.001, n=67\right)$.

It has been hypothesized that vitellogenesis in sea turtles is complete prior to the nesting season due to the drop in estradiol that occurs just prior to mating [21, 23, 45, 46]. Although in our study we were unable to measure vitellogenin in reproductively active females prior to nesting at Hutchinson Island, plasma concentration did decline as the nesting season progressed, suggesting that vitellogenesis indeed ceased prior to or early in the nesting season. However, vitellogenin has been observed to remain elevated in plasma for months after exogenous estrogen induction $[4,12$, 44], although the estrogen doses used were pharmacological; therefore, it is plausible that the protein remains elevated in 
wild animals for an extended period of time after natural vitellogenesis is complete. Additionally, toward the end of the nesting season vitellogenin concentration in nesting females remained elevated nearly 1,000 times that measured in nonreproductively active females (this study, [44]). This suggests that vitellogenesis may continue into the beginning of the nesting season. Recently, it was shown in captive loggerheads that although estradiol concentration is low during the nesting season in relation to the mating period, this steroid undergoes brief surges after every nesting event [24]. These pulsatile transient peaks in estradiol concentration are consistent with the maintenance of elevated vitellogenin through most of the nesting season that we observed in our wild turtles. This suggests that the ovary is very sensitive to estradiol, which is consistent with other studies [4, 12, 44]. It is tempting to postulate that elevated vitellogenin during the nesting season serves to prevent reabsorption of ovarian follicles, and not to support folliculogenesis, as the follicular size is fairly homogeneous at the onset of the season [46].

For reproductively active female sea turtles, the pronounced increase in testosterone concentration just prior to migration [20,23] may play a role in the cessation of vitellogenesis due to its inhibitory effects [14]. In this study, plasma testosterone concentrations declined as the nesting season progressed, which parallels the trends for both vitellogenin and estradiol concentration and is similar to data from other studies $[8,24]$. However, the functional relationship between testosterone and vitellogenesis remains ambiguous. We were unable to begin sampling until a month after the nesting season had begun and therefore we did not measure testosterone in females prior to migration. Perhaps analyses of blood samples collected prior to migration or just prior to the first nesting event could help clarify the relationship between vitellogenesis and steroid hormone concentration. Further examination of other reproductive hormones and hormone receptors in reproductively and nonreproductively active sea turtles, coupled with an expanded sampling period, would significantly contribute to an improved understanding of the reproductive physiology of female sea turtles.

All species of sea turtles exhibit a generally conserved sequence of behaviors during nesting, which consists of emergence on to the beach, digging the egg chamber, depositing eggs, then covering and camouflaging the egg chamber, and returning to sea [26]. However, it is common for nesting sea turtles to emerge on to the beach and then return to sea before ovipositing a clutch of eggs, a behavior frequently documented in loggerhead sea turtles nesting in the Southeastern USA [47]. There are several hypotheses as to why these turtles return to sea, such as unsatisfactory physiological or environmental conditions or debris obstructing their intended path. However, the actual reasons for this behavior remain unknown. In this study, we found no difference in vitellogenin concentration measured in nesting females that successfully oviposited, compared to vitellogenin concentration measured in nesting females that returned to sea before oviposition. Therefore, from the vitellogenin data stand point, females that emerged onto the beach but failed to nest may have been physiologically prepared to nest, but they aborted their effort for unknown reasons. This result was not unexpected, considering that turtles that return to sea before nesting are generally seen attempting to nest again within the next 24 hours [26].

4.2. In-Water Captures. We detected vitellogenin in $6 \%$ of the plasma samples from male and female loggerheads captured off the coast of the Southeast USA. While the concentrations of vitellogenin measured in these 22 turtles were significantly less than the lowest concentrations measured in nesting females, it is intriguing that these small amounts of vitellogenin were detected at all because five of those turtles were males and only two of the female turtles were of adult size. We did not expect to detect vitellogenin in this group of turtles, because they were presumably reproductively inactive due to their size and position within the foraging population [33].

One explanation for these findings is that turtles in this population have been exposed to environmental estrogen. Vitellogenin production is typical of reproductively active females, but male turtles also carry the vitellogenin gene. Induction of vitellogenesis in males exposed to exogenous estrogen has been shown in several reptilian species [4, $43,48]$. Because of this, vitellogenin is considered to be a biomarker of exposure to estrogenic contaminants in the environment that are classified as EDCs $[49,50]$. This group of chemicals interferes with the natural synthesis and functions of endogenous hormones, and this causes physiological and behavioral changes in otherwise healthy animals [27, 51-53]. The influence of EDCs may have serious implications for sea turtles considering that healthy, mature sea turtles exhibit distinct seasonal cycles in hormone production $[22,25,46,54,55]$. Accumulation of EDCs can cause unregulated or impaired hormone production, which may result in a wasteful use of energy reserves, leading to decreased overall health, decreased reproductive success, and overall decreased fitness [56]. Vitellogenin ELISAs have been developed for green and loggerhead sea turtles with the aim of using vitellogenin as an indicator of exposure to estrogenic contaminants [43,57]. However, a clear downfall with using vitellogenin as a biomarker in sea turtles is that the natural production of vitellogenin in these species has not been thoroughly described. Because of this, it would be difficult to distinguish between a nonreproductive female exposed to estrogenic contamination and a recrudescing female, although the vitellogenin ELISA coupled with the measurement of estrogenic pollutant load should work well to detect endocrine disruption in males and juveniles. An improved understanding of the role vitellogenin plays in the reproductive cycle may serve to more easily identify exposure of sea turtles to environmental estrogenic contaminants.

Plasma from one individual turtle from the in-water capture group yielded a significantly higher concentration of vitellogenin in comparison to all other turtles that had detectable vitellogenin. Since this individual was a relatively large female ( $>82 \mathrm{~cm} \mathrm{SCL})$, it is likely that this turtle was in an early stage of gonadal recrudescence. However, in 2 years of in-water sampling we did not capture more than 14 females greater than $82 \mathrm{~cm} \mathrm{SCL}$, of which only three individuals (including the above mentioned) had detectable vitellogenin. 
Due to the small sample size of larger size class females, and even fewer larger females with detectable vitellogenin, we were unable to generate sound conclusions regarding their reproductive status.

Since sea turtles do not exhibit sexual dimorphism until they approach reproductive maturity, it is difficult to predict the sex of immature animals. Plasma estrogen and testosterone concentrations are commonly used to predict or confirm the sex of juvenile sea turtles $[41,58,59]$. Although this method is generally reliable, it also requires the use of expensive and delicate assays. Discerning the ontogeny of vitellogenin may allow us to predict not only the sex of a juvenile turtle, but also when a female sea turtle is becoming reproductively mature and if (and possibly when) a reproductively active female will migrate, mate, and/or nest in a given season. In this way, vitellogenin concentration may help elucidate the reproductive status of maturing females through the use of minimally invasive techniques, such as our ELISA assay. More research is needed on larger size classes ( $>70 \mathrm{~cm} \mathrm{SCL}$ ) and both nesting and nonnesting female loggerhead sea turtles in order to better understand how vitellogenin production relates to reproductive development.

\section{Conclusions}

To our knowledge, this is the first study to systematically describe the seasonal production of vitellogenin in wild sea turtles. Through the development of an ELISA specific for loggerhead vitellogenin, we were able to measure the plasma concentration of vitellogenin in juvenile and nonreproductive and reproductive adult loggerhead sea turtles. Previous research hypothesized that vitellogenesis begins several months prior to the nesting season and is complete prior to the first nesting event for reproductively active female sea turtles. Our results indicate that while vitellogenin concentration declines as the nesting season progresses, it remains significantly elevated even at the end of the season. This seems to be the result of sporadic pulsatile production of estradiol during nesting season as observed in other studies. In addition, vitellogenin appears to have no relationship with whether or not an emerged female successfully nests or returns to sea before nesting. Vitellogenin was detected in male and juvenile turtles from the in-water captures, which may indicate exposure to endocrine disrupting compounds in this population. Continued research on the production of vitellogenin in sea turtles will be useful in assessing the reproductive status and health of these endangered species.

\section{Conflict of Interests}

The authors declare that there is no conflict of interests regarding the publication of this paper.

\section{Acknowledgments}

The authors are very grateful to many volunteers for their field and lab assistance, particularly Billie Poché and the researchers and staff members of Ecological Associates,
Inc., and the Loggerhead MarineLife Center of Juno Beach, Florida. This work could not have been done without many volunteers and crew members from the South Carolina Department of Natural Resources In-Water Sea Turtle Research program. They also thank Dr. Dave Owens for his valuable input into writing and proofreading this paper. This work was partially funded by LEQSF Grant (2006-09)-RDA-26 to R. Valverde.

\section{References}

[1] S. M. Ho, S. Kleis, R. McPherson, G. J. Heisermann, and I. P. Callard, "Regulation of vitellogenesis in reptiles," Herpetologica, vol. 38, no. 1, pp. 40-50, 1982.

[2] A. M. Polzonetti-Magni, G. Mosconi, L. Soverchia, S. Kikuyama, and O. Carnevali, "Multihormonal control of vitellogenesis in lower vertebrates," International Review of Cytology, vol. 239, pp. 1-46, 2004.

[3] M. B. Thompson and B. K. Speake, "Egg morphology and composition," in Reptilian Incubation: Environment, Evolution and Behaviour, D. C. Deeming, Ed., pp. 45-74, Nottingham University Press, Sheffield, UK, 2004.

[4] S. M. Ho, D. Danko, and I. P. Callard, "Effect of exogenous estradiol-17 $\beta$ on plasmas vitellogenin levels in male and female Chrysemys and its modulation by testosterone and progesterone," General and Comparative Endocrinology, vol. 43, no. 4, pp. 413-421, 1981.

[5] I. P. Callard, S. M. Ho, D. A. Gapp, S. Kleis, and G. Heisermann, "Regulation of vitellogenesis in reptiles: correlations with oviparity and viviparity," in Proceedings of the 9th International Symposium on Comparative Endocrinology, Current Trends in Comparative Endocrinology, pp. 359-361, Hong Kong, December 1985.

[6] J. Gavaud, "Vitellogenesis in the lizard Lacerta vivipara jacquin. II. Vitellogenin synthesis during the reproductive cycle and its control by ovarian steroids," General and Comparative Endocrinology, vol. 63, no. 1, pp. 11-23, 1986.

[7] X. Bonnet, G. Naulleau, and R. Mauget, "The influence of body condition on 17- $\beta$ estradiol levels in relation to vitellogenesis in female Vipera aspis (Reptilia, viperidae)," General and Comparative Endocrinology, vol. 93, no. 3, pp. 424-437, 1994.

[8] D. C. Rostal, J. S. Grumbles, K. S. Palmer, V. A. Lance, J. R. Spotila, and F. V. Paladino, "Changes in gonadal and adrenal steroid levels in the leatherback sea turtle (Dermochelys coriacea) during the nesting cycle," General and Comparative Endocrinology, vol. 122, no. 2, pp. 139-147, 2001.

[9] S. M. Ho, "Endocrinology of vitellogenesis," in Hormones and Reproduction in Fishes, Amphibians, and Reptiles, D. O. Norris and R. E. Jones, Eds., pp. 145-169, Springer, New York, NY, USA, 1987.

[10] E. W. Bergink and R. A. Wallace, "Precursor product relationship between amphibian vitellogenin and the yolk proteins, lipovitellin and phosvitin," Journal of Biological Chemistry, vol. 249, no. 9, pp. 2897-2903, 1974.

[11] R. G. Deeley, K. P. Mullinix, and W. Wetekam, "Vitellogenin synthesis in the avian liver. Vitellogenin is the precursor of the egg yolk phosphoproteins," Journal of Biological Chemistry, vol. 250, no. 23, pp. 9060-9066, 1975.

[12] J. Heck, D. S. MacKenzie, D. Rostal, K. Medler, and D. Owens, "Estrogen induction of plasma vitellogenin in the Kemp's ridley sea turtle (Lepidochelys kempi)," General and Comparative Endocrinology, vol. 107, no. 2, pp. 280-288, 1997. 
[13] I. P. Callard, D. Riley, and L. Perez, "Vertebrate vitellogenesis: molecular model for multihormonal control of gene regulation," Progress in Clinical and Biological Research, vol. 342, pp. 343$348,1990$.

[14] S. M. Ho, "Vitellogenesis," in Vertebrate Endocrinology: Fundamentals and Biomedical Implications, P. T. Pang and M. P. Schreibman, Eds., vol. 4 of Reproduction, pp. 91-126, Academic Press, San Diego, Calif, USA, 1991.

[15] G. Giannoukos and I. P. Callard, "Reptilian (Chrysemys picta) hepatic progesterone receptors: relationship to plasma steroids and the vitellogenic cycle," Journal of Steroid Biochemistry and Molecular Biology, vol. 55, no. 1, pp. 93-106, 1995.

[16] N. Custodia-Lora, A. Novillo, and I. P. Callard, "Regulation of hepatic progesterone and estrogen receptors in the female turtle, Chrysemys picta: relationship to vitellogenesis," General and Comparative Endocrinology, vol. 136, no. 2, pp. 232-240, 2004.

[17] A. E. Duggan and I. P. Callard, "Lipids and lipid-transporting proteins in Chrysemys picta: role of gonadal steroids and growth hormone in intact and hypophysectomized turtles," General and Comparative Endocrinology, vol. 131, no. 2, pp. 176-184, 2003.

[18] M. Paolucci, M. Rocco, and E. Varricchio, "Leptin presence in plasma, liver and fat bodies in the lizard Podarcis siculafluctuations throughout the reproductive cycle," Life Sciences, vol. 69, no. 20, pp. 2399-2408, 2001.

[19] E. Limatola and S. Filosa, "Exogenous vitellogenesis and micropinocytosis in the lizard, Podarcis sicula, treated with folliclestimulating hormone," General and Comparative Endocrinology, vol. 75, no. 2, pp. 165-176, 1989.

[20] D. W. Owens, "Hormones in the life history of sea turtles," in The Biology of Sea Turtles, P. L. Lutz and J. A. Musick, Eds., pp. 315-341, CRC Press, Boca Raton, Fla, USA, 1997.

[21] P. Licht, W. Rainey, and K. Cliffton, "Serum gonadotropin and steroids associated with breeding activities in the green sea turtle, Chelonia mydas. II. Mating and nesting in natural populations," General and Comparative Endocrinology, vol. 40, no. 1, pp. 116-122, 1980.

[22] D. W. Owens and Y. A. Morris, "The comparative endocrinology of sea turtles," Copeia, pp. 723-735, 1985.

[23] T. Wibbels, D.-W. Owens, C. J. Limpus, P. C. Reed, and M. S. Amoss Jr., "Seasonal changes in serum gonadal steroids associated with migration, mating, and nesting in the loggerhead sea turtle (Caretta caretta)," General and Comparative Endocrinology, vol. 79, no. 1, pp. 154-164, 1990.

[24] Y. Kakizoe, M. Fujiwara, Y. Akune, Y. Kanou, T. Saito, and I. Uchida, "Cyclical changes of plasma sex steroids in captive breeding loggerhead turtles (Caretta caretta)," Journal of Zoo and Wildlife Medicine, vol. 41, no. 4, pp. 643-648, 2010.

[25] A. A. Al-Habsi, A. Y. A. AlKindi, I. Y. Mahmoud, D. W. Owens, T. Khan, and A. al-Abri, "Plasma hormone levels in the green turtles Chelonia mydas during peak period of nesting at Ras AlHadd-Oman," Journal of Endocrinology, vol. 191, no. 1, pp. 9-14, 2006.

[26] J. D. Miller, "Reproduction in sea turtles," in The Biology of Sea Turtles, P. L. Lutz and J. A. Musick, Eds., pp. 51-81, CRC Press, Boca Raton, Fla, USA, 1997.

[27] D. Crews, E. Willingham, and J. K. Skipper, "Endocrine disruptors: present issues, future directions," Quarterly Review of Biology, vol. 75, no. 3, pp. 243-260, 2000.

[28] L. M. Ehrhart, D. A. Bagley, and W. A. Redfoot, "Loggerhead turtles in the Atlantic Ocean: geographic distribution, abundance, and population status," in Loggerhead Sea Turtles, A. B.
Bolten and B. E. Witherington, Eds., pp. 157-174, Smithsonian Books, Washington, DC, USA, 2003.

[29] A. B. Bolten, "Active swimmers-passive drifters: the oceanic juvenile stage of loggerheads in the Atlantic system," in Loggerhead Sea Turtles, A. B. Bolten and B. E. Witherington, Eds., pp. 63-78, Smithsonian Books, Washington, DC, USA, 2003.

[30] B. A. Schroeder, A. M. Foley, and D. A. Bagley, "Nesting patterns, reproductive migrations, and adult foraging areas of loggerhead turtles," in Loggerhead Sea Turtles, A. B. Bolten and B. E. Witherington, Eds., pp. 114-124, Smithsonian Books, Washington, DC, USA, 2003.

[31] USFWS and NMFS, Endangered and Threatened Species, Determination of Nine Distinct Population Segments of Loggerhead Sea Turtles as Endangered or Threatened, 2011.

[32] A. Carr, "New perspectives on the pelagic stage of sea turtle development," Conservation Biology, vol. 1, no. 2, pp. 103-121, 1987.

[33] S. R. Hopkins-Murphy, D. W. Owens, and T. M. Murphy, "Ecology of immature loggerheads on foraging grounds and adults in internesting habitat in the Eastern United States," in Loggerhead Sea Turtles, A. B. Bolten and B. E. Witherington, Eds., pp. 79-92, Smithsonian Books, Washington, DC, USA, 2003.

[34] L. M. Ehrhart and R. G. Yoder, "Marine turtles of Merritt Island National Wildlife Refuge, Kennedy Space Center, Florida," in Proceedings of the Florida and Interregional Conference on Sea Turtles, Florida Marine Research Publications no. 33, pp. 25-30, Jensen Beach, Fla, USA, July 1976.

[35] D. L. Stoneburner, "Body depth: an indicator of morphological variation among nesting groups of adult loggerhead sea turtles (Caretta caretta)," Journal of Herpetology, vol. 14, no. 2, pp. 205206, 1980.

[36] N. Williams-Walls, J. O’Hara, R. M. Gallagher, D. F. Worth, B. D. Perry, and J. R. Wilcox, "Spatial and temporal trends of sea turtle nesting on Hutchinson Island, Florida, 1971-1979 (Caretta caretta)," Bulletin of Marine Science, vol. 33, no. 1, pp. 55-66, 1983.

[37] N. Kamezaki, "What is a loggerhead turtle? The morphological perspective," in Loggerhead Sea Turtles, A. B. Bolten and B. E. Witherington, Eds., pp. 28-43, Smithsonian Books, Washington, DC, USA, 2003.

[38] TEWG (Turtle Expert Working Group), "An assessment of the loggerhead turtle population in the Western North Atlantic Ocean," NOAA Technical Memorandum NMFS-SEFSC-575, 2009.

[39] D. W. Owens and G. J. Ruiz, "New methods of obtaining blood and cerebrospinal fluid from marine turtles," Herpetologica, vol. 36, pp. 17-20, 1980.

[40] M. D. Arendt, J. Boynton, J. A. Schwenter et al., "Spatial clustering of loggerhead sea turtles in coastal waters of the NW Atlantic Ocean: implications for management surveys," Endangered Species Research, vol. 18, no. 3, pp. 219-231, 2012.

[41] G. Blanvillain, A. P. Pease, A. L. Segars, D. C. Rostal, A. J. Richards, and D. W. Owens, "Comparing methods for the assessment of reproductive activity in adult male loggerhead sea turtles Caretta caretta at Cape Canaveral, Florida," Endangered Species Research, vol. 6, no. 1, pp. 75-85, 2008.

[42] B. D. Palmer, L. K. Huth, D. L. Pieto, and K. W. Selcer, "Vitellogenin as a biomarker for xenobiotic estrogens in an amphibian model system," Environmental Toxicology and Chemistry, vol. 17, no. 1, pp. 30-36, 1998. 
[43] I. Sifuentes-Romero, C. Vázquez-Boucard, A. P. Sierra-Beltrán, and S. C. Gardner, "Vitellogenin in black turtle (Chelonia mydas agassizii): purification, partial characterization, and validation of an enzyme-linked immunosorbent assay for its detection," Environmental Toxicology and Chemistry, vol. 25, no. 2, pp. 477485, 2006.

[44] L. H. Herbst, L. Siconolfi-Baez, J. H. Torelli, P. A. Klein, M. J. Kerben, and I. M. Schumacher, "Induction of vitellogenesis by estradiol-17 $\beta$ and development of enzyme-linked immunosorbant assays to quantify plasma vitellogenin levels in green turtles (Chelonia mydas)," Comparative Biochemistry and Physiology B, vol. 135, no. 3, pp. 551-563, 2003.

[45] D. C. Rostal, F. V. Paladino, R. M. Patterson, and J. R. Spotila, "Reproductive physiology of nesting leatherback turtles (Dermochelys coriacea) at Las Baulas National Park, Costa Rica," Chelonian Conservation and Biology, vol. 22, pp. 230-236, 1996.

[46] D. C. Rostal, D. W. Owens, J. S. Grumbles, D. S. MacKenzie, and M. S. Amoss Jr., "Seasonal reproductive cycle of the Kemp's ridley sea turtle (Lepidochelys kempi)," General and Comparative Endocrinology, vol. 109, no. 2, pp. 232-243, 1998.

[47] C. K. Dodd Jr., "Synopsis of the biological data on the loggerhead sea turtle Caretta caretta (Linnaeus 1758)," U.S. Fish and Wildife Service Biological Report, vol. 88, no. 1-8, pp. 1-110, 1988.

[48] B. D. Palmer and S. K. Palmer, "Vitellogenin induction by xenobiotic estrogens in the red-eared turtle and African clawed frog," Environmental Health Perspectives, vol. 103, supplement 4, pp. 19-25, 1995.

[49] P.-D. Hansen, H. Dizer, B. Hock et al., "Vitellogenin-a biomarker for endocrine disruptors," Trends in Analytical Chemistry, vol. 17, no. 7, pp. 448-451, 1998.

[50] N. D. Denslow, M. C. Chow, K. J. Kroll, and L. Green, "Vitellogenin as a biomarker of exposure for estrogen or estrogen mimics," Ecotoxicology, vol. 8, no. 5, pp. 385-398, 1999.

[51] D. Hollander, "Environmental effects on reproductive health: the endocrine disruption hypothesis," Family Planning Perspectives, vol. 29, no. 2, pp. 82-89, 1997.

[52] T. B. Hayes, "Welcome to the revolution: integrative biology and assessing the impact of endocrine disruptors on environmental and public health," Integrative and Comparative Biology, vol. 45, no. 2, pp. 321-329, 2005.

[53] D. O. Norris and J. A. Carr, Endocrine Disruption: Biological Bases for Health Effects in Wildlife and Humans, Oxford University Press, New York, NY, USA, 2005.

[54] T. Wibbels, D. W. Owens, P. Licht, C. Limpus, P. C. Reed, and M. S. Amoss Jr., "Serum gonadotropins and gonadal steroids associated with ovulation and egg production in sea turtles," General and Comparative Endocrinology, vol. 87, no. 1, pp. 71-78, 1992.

[55] K. A. Dobbs, J. D. Miller, D. W. Owens, and J. Landry, "Serum testosterone and estradiol-17 $\beta$ levels during the peak period in a year-round Hawksbill Turtle Eretmochelys imbricata L. nesting population," Pacific Conservation Biology, vol. 13, no. 3, pp. 151157, 2007.

[56] A. Arukwe and A. Goksøyr, "Eggshell and egg yolk proteins in fish: hepatic proteins for the next generation: oogenetic, population, and evolutionary implications of endocrine disruption," Comparative Hepatology, vol. 2, article 4, 2003.

[57] A. Zaccaroni, M. Zucchini, L. Segatta et al., "Vitellogenin (VTG) conservation in sea turtles: anti-VTG antibody in Chelonia mydas versus Caretta caretta," Physiological and Biochemical Zoology, vol. 83, no. 1, pp. 191-195, 2010.

[58] J. Braun-Mcneill, S. P. Epperly, D. W. Owens, L. Avens, E. Williams, and C. A. Harms, "Seasonal reliability of testosterone radioimmunoassay (RIA) for predicting sex ratios of juvenile loggerhead (Caretta caretta) turtles," Herpetologica, vol. 63, no. 3, pp. 275-284, 2007.

[59] L. F. Gregory and J. R. Schmid, "Stress responses and sexing of wild Kemp's ridley sea turtles (Lepidochelys kempii) in the Northeastern Gulf of Mexico," General and Comparative Endocrinology, vol. 124, no. 1, pp. 66-74, 2001. 

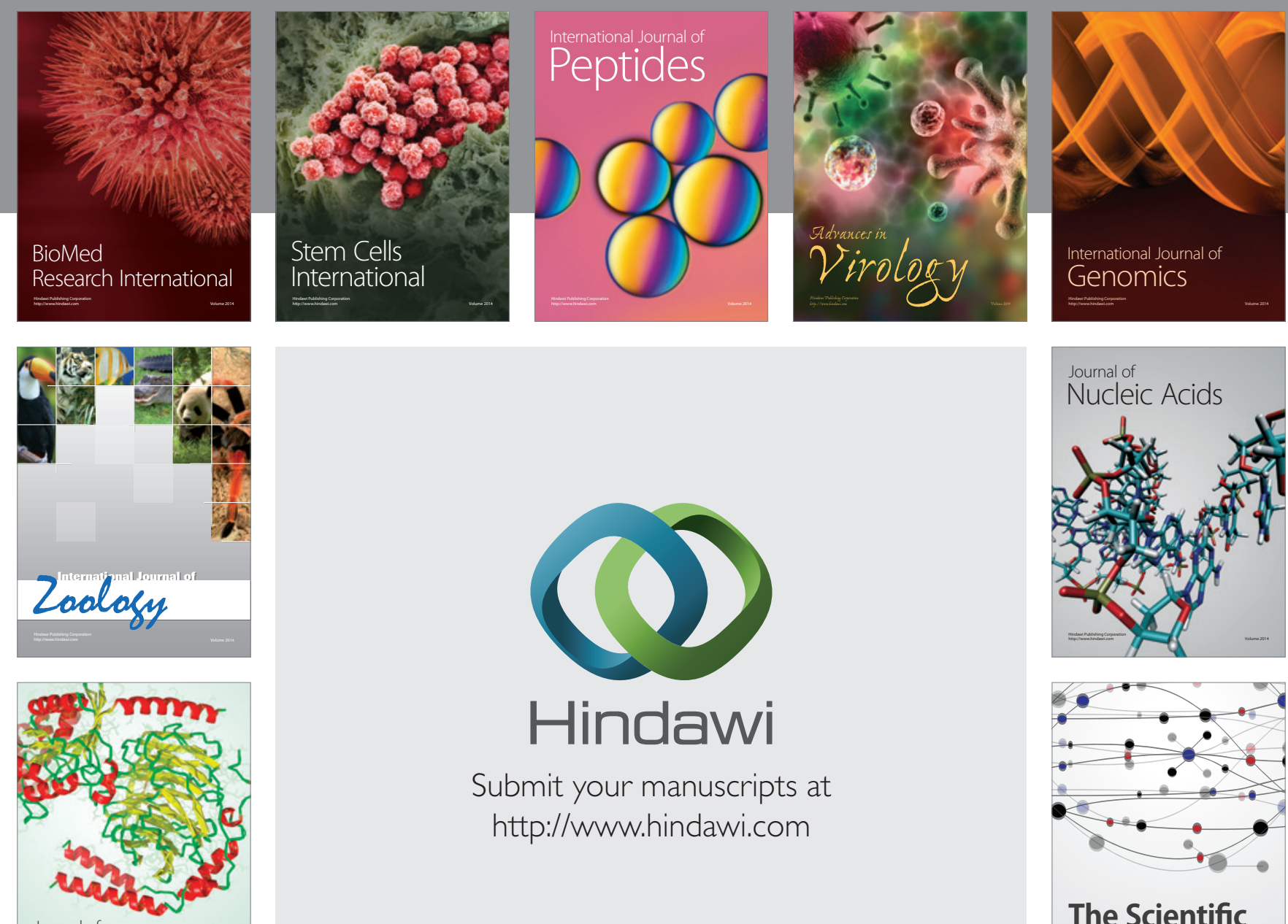

Submit your manuscripts at

http://www.hindawi.com

Journal of
Signal Transduction
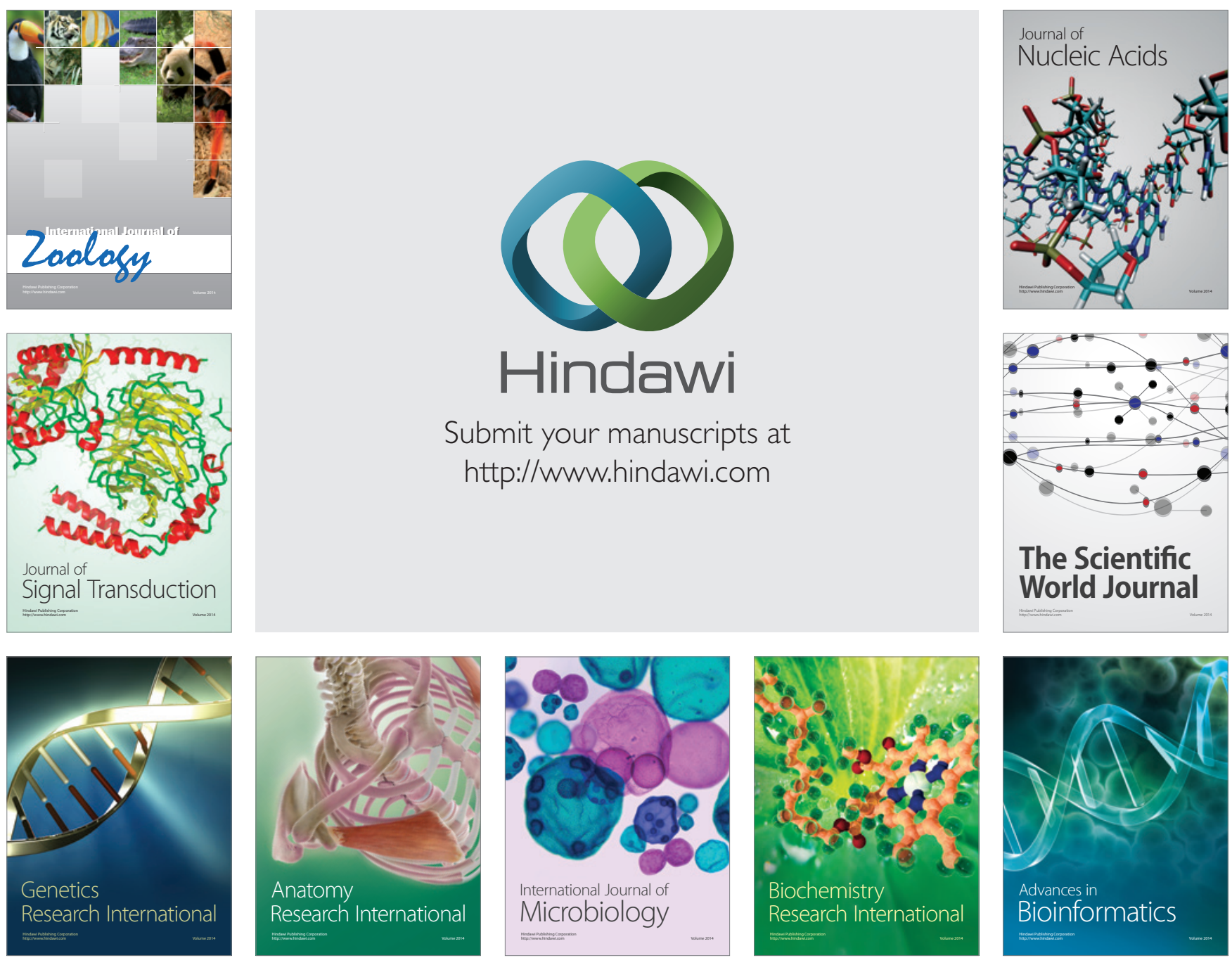

The Scientific World Journal
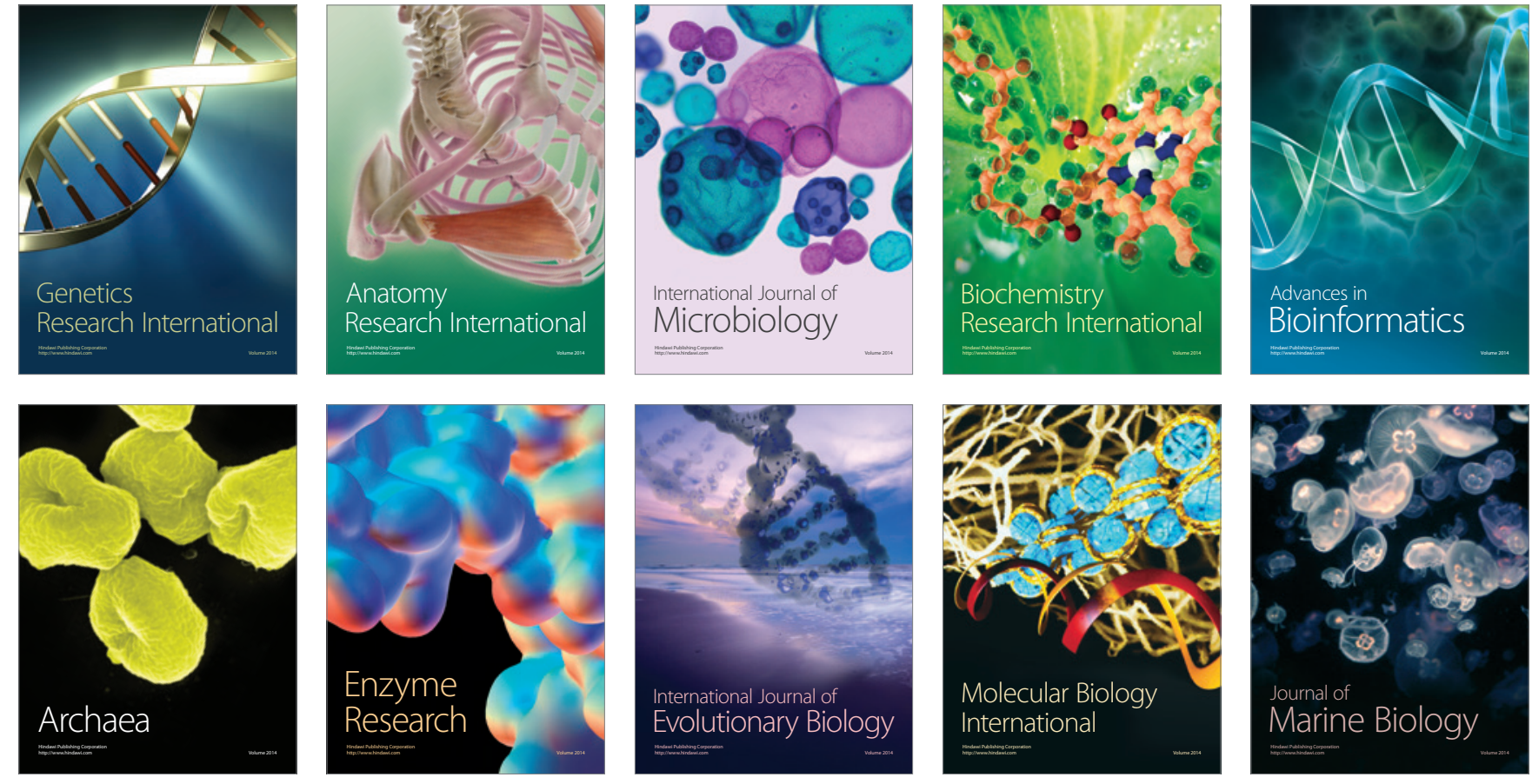